\title{
Organização de Informações via Pensamento Computacional: Relato de Atividade Aplicada no Ensino Fundamental ${ }^{*}$
}

\author{
Gleider M. de Campos, Simone Cavalheiro, Luciana Foss, Ana Marilza Pernas, \\ Clause Fátima de Brum Piana, Marilton Aguiar, André Du Bois , Renata Reiser \\ ${ }^{1}$ Centro de Desenvolvimento Tecnológico - Universidade Federal de Pelotas (UFPel) \\ Rua Gomes Carneiro, 1 - 96.010-610 - Pelotas - RS - Brasil \\ \{gmdcampos, simone.costa\}@inf.ufpel.edu.br
}

\begin{abstract}
Technological innovations have changed the profile of professionals required by economy sectors demanding skills related to problem solving and logical thinking. Concurrently with this reality, Computational Thinking emerges as a methodology for solving problems, which is able to develop many of these skills. This article proposes a methodology for the activity referred as Binary Numbers, which aims at developing necessary skills for the prac- tice of Computational Thinking in fourth-grade children. The article details the development of the activity and evaluates the obtained results.
\end{abstract}

Resumo. As inovações tecnológicas mudaram o perfil do profissional requerido pelos setores da economia, exigindo habilidades relacionadas a solução de problemas e pensamento lógico. Concomitante a esta realidade, surge o Pensamento Computacional, uma metodologia para solução de problemas capaz de desenvolver muitas destas habilidades. Este artigo apresenta uma proposta metodológica para a atividade referida como Números Binários, que visa desenvolver habilidades necessárias para prática do Pensamento Computacional em crianças do quarto ano. $O$ artigo detalha o seu desenvolvimento em sala de aula e avalia os resultados obtidos.

\section{Introdução}

A definição amplamente aceita para Pensamento Computacional (computational thinking) foi apresentada por Jeannette Wing em [Wing 2006], à época chefe do Departamento de Ciência da Computação da Universidade de Carnegie Mellon. Pensamento Computacional (PC) utiliza os conceitos básicos da Ciência da Computação para resolver problemas, desenvolver sistemas e para entender o comportamento humano. De forma geral, as habilidades aplicadas originalmente na criação de programas computacionais são utilizadas para resolver problemas específicos como uma metodologia para resolver problemas gerais nas mais diversas áreas do conhecimento [Bundy 2007, Denning 2009, Nunes 2011].

Wing afirma que o PC é um pensamento do ser humano, ao invés de um pensamento mecânico ou de máquina. Caracteriza-se como um pensamento conceitualizado, ao invés de um pensamento programado, consistindo em um modo de pensar, ao invés de um produto. Mais que uma especialidade dos cientistas da

*Projeto realizado com o apoio do PROEXT - MEC/SESu, PICMEL - FAPERGS (Proc. 0356-2551/144) e da Universidade Federal de Pelotas (UFPel) 
computação [Yinnan and Chaosheng 2012], PC se constitui em uma habilidade básica do ser humano. Neste contexto, o PC pode ser colocado como uma das habilidades intelectuais fundamentais, comparada a ler, escrever, falar ou fazer operações aritméticas.

O PC requer um pensamento abstrato de alto nível via habilidades importantes para que os indivíduos tenham sucesso na vida moderna. Sendo um novo modo de pensar e de resolver problemas, e considerando os indivíduos como mais inteligentes e imaginativos que os computadores, a manipulação de dispositivos computacionais via PC nos habilita a resolver problemas insolúveis antes da era da computação, alcançando o estado de "apenas impensável, não impossível" [Yinnan and Chaosheng 2012].

As escolas de ensino fundamental são veículos relevantes para implantação do uso do PC, no sentido de incentivar habilidades para desenvolvimento pleno e efetivo do raciocínio lógico-dedutível, principalmente nos primeiros anos escolares. Nas empresas multinacionais, como Google e Microsoft, surgem projetos para promoção do PC em diversos níveis de ensino. Particularmente, a Google [Google 2013] propõe um conjunto de atividades de PC para auxiliar alunos do ensino primário e secundário dos EUA. No Brasil, também surgiram iniciativas nesta direção. Apesar da temática já estar sendo veiculada em artigos nacionais [Nunes 2011, França and Amaral 2013] e da existência de projetos [Bell et al. 2010, PUC-Rio 2013] de universidades brasileiras visando introduzir os fundamentos da computação em escolas, apresenta-se um desenvolvimento ainda seminal no nível educacional e governamental para implantação do PC na educação básica.

Este artigo apresenta os principais resultados de uma aplicação piloto pela definição e aplicação de metodologia adequada para representação de dados via PC para estudantes de quarto ano do Ensino Fundamental.

O artigo está organizado como segue. A Seção 2 apresenta um breve referencial teórico no que tange o PC. Na Seção 3 é apresentada a metodologia utilizada para o desenvolvimento da atividade, tratando da criação do material, plano de aula e adequação ao cenário da escola. A Seção 4 relata a aplicação da atividade em duas turmas do Ensino Fundamental, incluindo a descrição das turmas e a análise dos resultados obtidos. Por fim, a Seção 5 apresenta as principais conclusões acerca do trabalho.

\section{Pensamento Computacional}

A Sociedade Internacional de Tecnologia na Educação (ISTE) inclui habilidades específicas (mas não limita a estas) na definição operacional de PC para Educação no Ensino Fundamental e Médio [ISTE 2013, Deng et al. 2009]: i) reformular (por redução, simulação ou transformação) um problema aparentemente difícil em um outro com solução conhecida; ii) pensar recursivamente e processar em paralelo uma abordagem de interpretação de dados e códigos; iii) utilizar abstração e decomposição para resolver uma tarefa complexa, via análise por partes; iv) escolher uma representação apropriada para um problema ou modelar aspectos relevantes de um problema tornando-o tratável; v) pensar em prevenção, proteção e recuperação em cenários de pior-caso utilizando conceitos de redundância, redução de danos e correção de erros; vi) utilizar raciocínio heurístico para achar soluções, planejando, aprendendo e escalonado na presença da incerteza; vii) reunir informação para acelerar o processo de solução e de computação.

Visando a competência em habilidades básicas do PC na conclusão do ensino médio, um conjunto de ferramentas denominado Computational Thinking in K-12 Edu- 
cation Leadership Toolkit [CSTA et al. 2010] foi desenvolvido por líderes de diferentes escolas, em conjunto com a ISTE, a Computer Science Teachers Association (CSTA) e a National Science Foundation (NSF). O toolkit apresenta uma fundamentação teórica para o processo de desenvolvimento do $\mathrm{PC}$ e dos recursos necessários para uma mudança sistemática. Neste toolkit, destaca-se o quadro de progressão com nove conceitos da computação fundamentais para o desenvolvimento do PC: coleta de dados, análise de dados, representação de dados, decomposição de problemas, algoritmos e procedimentos, automação, simulação e paralelismo.

Diversos programas e projetos com foco no desenvolvimento de atividades para o desenvolvimento do PC nos diversos níveis de ensino podem ser citados [Barr and Stephenson 2011, Bell et al. 2010, Carnegie Mellon 2013, França and Amaral 2013, Google 2013, Hambrusch et al. 2009, Lee et al. 2011, Kafura and Tatar 2011, Repenning et al. 2010]. No Brasil, é possível destacar pelo menos três projetos voltados à introdução do PC no âmbito do ensino básico: o Game Design Brasil, vinculado a PUC-RJ, tem como objetivo o desenvolvimento de uma tecnologia brasileira para estimular o ensino-aprendizado de computação em escolas de ensino fundamental e médio [PUC-Rio 2013]; o Computação Desplugada, que tem como meta propagar os fundamentos da ciência da computação sem o uso de computador, para alunos de escolas públicas [Scaico et al. 2012]; e, o EXP-PC - Explorando o Pensamento Computacional para a Qualificação do Ensino Fundamental [UFPel 2014], que visa a elaboração e a aplicação de atividades que desenvolvam conceitos considerados essenciais no PC [Andrade et al. 2013].

\section{Metodologia de Desenvolvimento da Atividade}

O desenvolvimento da atividade proposta usou como base o material disponível no livro Computer Science Unplugged [Bell et al. 2010], elaborado pelas Universidades de Carnegie Mellon e de Canterbury, com apoio da empresa Google. O livro descreve 20 propostas de atividades a serem aplicadas em sala de aula visando ao ensino de tópicos fundamentais da Ciência Computação de maneira lúdica e sem o uso do computador.

Neste trabalho, estende-se a primeira destas atividades, referida como Números Binários (NB), que objetiva trabalhar os conceitos de abstração e representação de dados. A extensão foi proposta para trabalhar com crianças do quarto ano (faixa etária 9 a 13 anos) do Ensino Fundamental, visando colaborar com o desenvolvimento de habilidades como representar, contar, correlacionar e ordenar. Em [Bell et al. 2010], tem-se apenas uma descrição geral da atividade, com sugestões de materiais e discussões a serem levantadas com os alunos durante a prática. Nesta seção é apresentada uma proposta metodológica para a referida atividade NB, incluindo a descrição detalhada do seu desenvolvimento em sala de aula.

Em sua proposta, buscou-se maneiras de aplicar a atividade de forma lúdica, viabilizando uma metodologia que fosse compreensível ao nível do quarto ano de uma escola pública. A atividade foi idealizada para aplicação com periodicidade semanal, em intervalo de 1 hora e 30 minutos, sendo organizada em três tarefas, cada uma com conceitos e exercícios específicos. Detalhes a respeito do material desenvolvido (com fotos e passo a passo) e os planos detalhados podem ser obtidos na wiki do projeto ${ }^{1}$.

\footnotetext{
${ }^{1}$ http://goo.gl/t3nkGQ
} 
Para mensurar o incremento da aprendizagem discente relativo às habilidades do PC propostas no projeto, elaborou-se um teste que foi aplicado em dois momentos: antes do início (pré-teste) e depois da conclusão (pós-teste) de todas as atividades. O teste compreende quatro questões, duas das quais (ilustradas na Figura 1) valendo $50 \%$ da pontuação. Salienta-se que habilidades como abstrair, correlacionar e codificar dados foram consideradas.

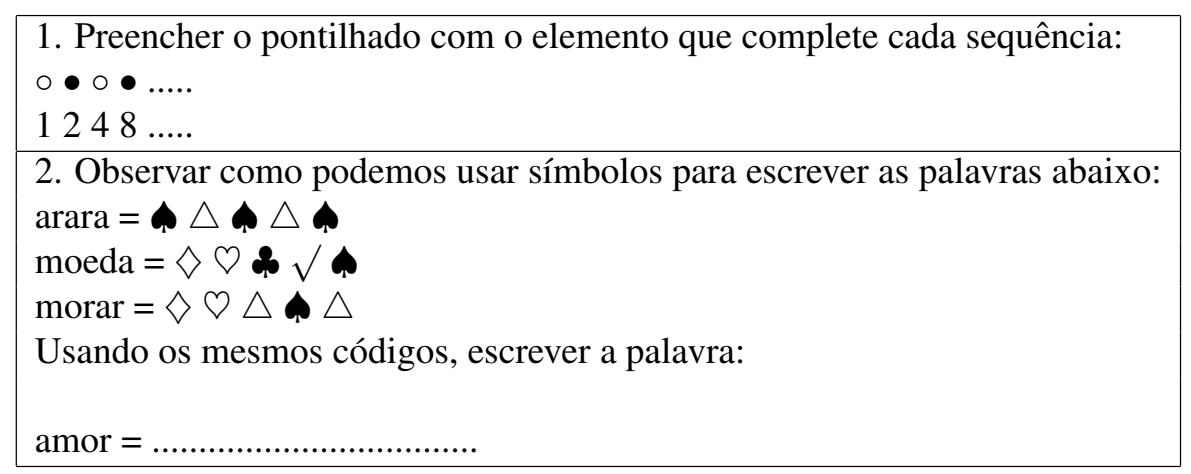

Figura 1. Teste Inicial e Final

\subsection{Tarefa I - Transformação de Código Binário para Número Decimal}

Motivação: é buscada através da criação de um clubinho secreto. Para participarem deste clubinho, precisam descobrir um número secreto a partir de um código binário dado. A proposta da aula é ensiná-los a decodificar códigos binários em números secretos.

Criação do Material: a atividade é apresentada com uso de tabuleiros e, para cada tabuleiro, cinco cartas coloridas (com 1, 2, 4, 8 e 16 pontos pretos). Uma versão ampliada do material foi confeccionada para demonstração no quadro e uma versão menor para cada um dos alunos. A versão dos alunos está ilustrada na Figura 2. As cartas possuem cores diferentes e cada uma possui, de um lado, pontinhos pretos. O tabuleiro do professor pode ser confeccionado em EVA e as cartas em papel color plus A4 180g.

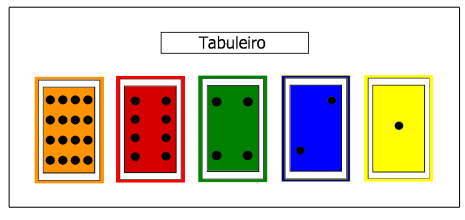

(a) Tabuleiro com Cartas

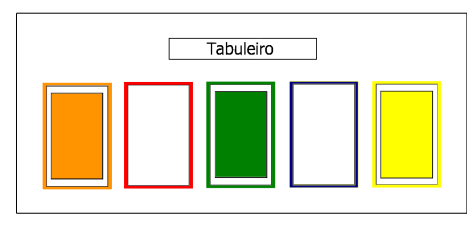

(b) Binário 10101

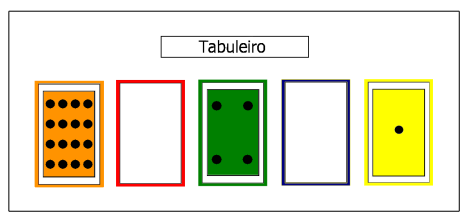

(c) Decimal 21

Figura 2. Material do Aluno

Metodologia: cada aluno recebe cinco cartas e um tabuleiro. Deve-se enfatizar que cada espaço do tabuleiro tem uma cor diferente e que cada carta só pode ser colocada no espaço de mesma cor. Inicialmente, deve-se apresentar aos alunos o código binário, que constitui uma sequência de cinco dígitos formada de 0's ou 1's. Alguns exemplos e contra-exemplos devem ser mostrados. A próxima etapa consiste em colocar as cartas no tabuleiro, sendo o código binário escrito embaixo do tabuleiro grande no quadro. Então, se explica como o binário pode ser representado no tabuleiro: quando o dígito do código for 0 , não se deve colocar a carta correspondente, e quando for 1 deve-se colocá-la. A próxima etapa consiste em descobrir qual o número secreto que o código representa. Para 
isso, as cartas devem ser viradas os pontos pretos contados. Os alunos devem acompanhar o processo usando o seu material e seguindo as orientações do professor.

Avaliação: como exercício desta tarefa, os alunos devem preencher o número secreto com base nos tabuleiros desenhados (são ilustrados tabuleiros que representam os decimais de 0 até 31). A avaliação da tarefa é composta por três questões análogas aos exercícios.

\subsection{Tarefa II - Transformação de Código Binário para Palavras}

Motivação: é proposto que os membros do clube se comuniquem através de códigos binários, onde cada código se refere a um número e este número corresponde a uma letra.

Criação do Material: foi usado o material da Tarefa I e confeccionada uma tabela associando os números decimais de 1 a 26 às letras (de A a Z, respectivamente).

Metodologia: explica-se aos alunos que, além do clubinho, o código binário é também utilizado pelos computadores, celulares e outras máquinas, e que nesta aula será ensinado como transformar códigos binários em letras. Utilizando um código, por exemplo o binário "00001", com a ajuda das cartas e do tabuleiro, os alunos chegam ao número secreto 1 e, utilizando a tabela que referencia o número com uma letra, chegam à letra A. Desta mesma forma, sugere-se realizar outros exemplos. Em seguida, começa-se a traduzir códigos binários em palavras.

Avaliação: aplicam-se exercícios similares aos da Tarefa I, associando a cada código binário uma letra. Segue-se a avaliação, com três questões análogas aos exercícios.

\subsection{Tarefa III - Transformação de Letra para Código Binário}

Motivação: é feita a analogia com o envio de mensagens por um celular, onde escreve-se uma frase, o celular transforma em binário e envia para outro celular, que por sua vez transforma novamente em palavras para serem lidas pelo receptor. A proposta é que os alunos convertam letras em códigos binários, aprendendo a escrever em binário.

Criação do Material: o material a ser utilizado é o mesmo das tarefas anteriores.

Metodologia: propõe-se que os alunos simulem o papel de um celular. Para isso, recebem duas folhas onde, na primeira, cada aluno escreve seu nome e sua fruta preferida. Para cada letra, preenchem o número secreto e, usando o material, transformam cada número em um código binário. Após, a folha contendo apenas o código binário de um aluno deve ser entregue aleatoriamente para outro aluno, o qual deve decifrar a mensagem em binário. A seguir, apresenta-se aos alunos a forma de descoberta do código binário sem utilização de tabuleiro e cartas, mas através do método de divisões sucessivas.

Avaliação: realiza-se o exercício de simulação da mensagem de celular. Na avaliação constam exercícios de conversão de palavra e frase para código binário e a conversão de decimal para binário através do método das divisões sucessivas.

\section{Aplicação da Atividade e Resultados}

As decisões tomadas para a aplicação da atividade consideraram reuniões com a Secretaria Municipal de Educação e Desporto de Pelotas. Optou-se por desenvolver a atividade em uma escola de Ensino Fundamental da rede pública da cidade e que fosse próxima à Universidade para facilitar o deslocamento dos participantes do projeto, visto a não existência de financiamento para a realização das práticas na escola. 
Por atender estes critérios, a escola escolhida foi a Escola Municipal de Ensino Fundamental Ferreira Viana. Após a escolha, foram iniciadas reuniões com a diretoria e a coordenação da escola, para identificar os perfis das turmas a serem trabalhadas bem como elaborar um cronograma prévio de trabalho. Decidiu-se trabalhar com duas turmas de $4^{\circ}$ ano devido à necessidade de que os alunos soubessem ler, escrever e conhecessem as operações aritméticas básicas. A atividade foi, então, aplicada em uma turma do turno da manhã (22 alunos) e outra da tarde (24 alunos). A idade dos alunos variou entre 9 e 13 anos, mas a grande maioria (82\%) tinha 9 ou 10 anos de idade. Com relação ao sexo, $63 \%$ dos alunos era do sexo masculino enquanto que $37 \%$ era do sexo feminino.

Com relação ao cronograma, os encontros da atividade NB foram realizados no mês de Setembro de 2013, totalizando cinco encontros (um por semana), sendo dois para preparação da turma (pré e pós-teste) e três para desenvolvimento da atividade (um encontro para cada tarefa) e avaliações. A prática da atividade NB foi iniciada no segundo encontro, após a aplicação do pré-teste.

As tarefas da atividade foram ministradas seguindo a metodologia apresentada na Seção 3. Os encontros foram realizados com a presença de dois a três alunos bolsistas, um deles responsável por ministrar o conteúdo, um responsável por apoiar na apresentação do material da atividade (somente quando necessário) e um responsável por auxiliar individualmente os alunos, quando requisitado por estes. Além dos bolsistas, dois professores responsáveis pelo projeto estavam presentes na atividade, para apoio quando necessário, e a professora da turma, cuja presença foi importante por conhecer o comportamento da turma e as características pessoais de cada aluno.

Os resultados obtidos são apresentados e discutidos nas próximas seções.

\subsection{Resultados das Avaliações das Tarefas}

A descrição da pontuação dos alunos nas avaliações das tarefas 1,2 e 3 é apresentada na Tabela 1, por turma e geral, por questão e total. As avaliações pretenderam avaliar os conceitos de contagem, correlação e ordenação. Note-se que em razão das tarefas terem sido realizadas em dias diferentes, o número de alunos avaliados variou entre as tarefas. Do total de alunos, 41 fizeram a tarefa 1,37 a tarefa 2 e apenas 20 a tarefa 3.

A avaliação da tarefa 1 compreendeu três questões, 1, 2 e 3, valendo 3, 4 e 3 pontos, respectivamente. Verifica-se na Tabela 1 que, em ambas as turmas, todos os alunos alcançaram pontuação máxima na questão 1 ; na questão 2 , pelo menos, $75 \%$ dos alunos da turma da manha e $50 \%$ da turma da tarde obtiveram pontuação máxima, as médias das turmas foram 3,90 e 3,68, respectivamente. O desempenho na questão 3 revelou a maior diferença entre as turmas: a pontuação dos alunos variou entre 2 e 3, com média 2,95, para a turma da manhã e para a turma da tarde variou de 0 a 3 com media 2,1 . O total de pontos por turma na tarefa 1 evidencia que o desempenho da turma da manhã foi superior e mais homogêneo (média 9,9 e desvio padrão 0,31) do que o desempenho da turma da tarde (média 8,8 e desvio padrão 1,15).

A avaliação da tarefa 2 foi formada por três questões, 1, 2 e 3, valendo 2,4, 4,6 e 3,0 pontos, respectivamente. Todos os alunos da turma da manhã e $89 \%$ dos alunos da turma da tarde acertaram integralmente a questão 1 . O inverso foi observado na questão 3: todos os alunos da turma da tarde e $89 \%$ dos alunos da turma da manhã acertaram toda a questão. Na questão 2 pelo menos $75 \%$ de ambas as turmas alcançou pontuação máxima. 
Pela pontuação total dos alunos na avaliação da tarefa 2, verifica-se que ambas as turmas tiveram um desempenho semelhante. A turma da tarde apresentou média 9,44 e desvio padrão 1,18 e a turma da tarde, média 9,61 e desvio padrão 1,04.

Tabela 1. Desempenho dos alunos nas Tarefas 1,2 e 3 por turma e geral.

\begin{tabular}{|c|c|c|c|c|c|c|c|c|c|c|}
\hline Tarefa & Turma & Questão & $\mathrm{n}$ & Média & $\mathrm{DP}$ & Min & $Q_{1}$ & Md & $Q_{3}$ & Max \\
\hline \multirow{12}{*}{1} & \multirow{4}{*}{ Manhã } & 1 & \multirow{3}{*}{21} & 3,00 & 0,00 & 3 & 3 & 3 & 3 & 3 \\
\hline & & 2 & & 3,90 & 0,31 & 2,6 & 3,4 & 4 & 4 & 4 \\
\hline & & 3 & & 2,95 & 0,22 & 2 & 3 & 3 & 3 & 3 \\
\hline & & \multicolumn{2}{|c|}{ Total } & 9,90 & 0,31 & 8,6 & 9,95 & 10 & 10 & 10 \\
\hline & \multirow{4}{*}{ Tarde } & 1 & \multirow{3}{*}{20} & 3,00 & 0,00 & 3 & 3 & 3 & 3 & 3 \\
\hline & & 2 & & 3,68 & 0,69 & 1,3 & 3,8 & 4 & 4 & 4 \\
\hline & & 3 & & 2,10 & 1,02 & 0 & 1 & 2,5 & 3 & 3 \\
\hline & & \multicolumn{2}{|c|}{ Total } & 8,78 & 1,15 & 6,3 & 8 & 8,75 & 10 & 10 \\
\hline & \multirow{4}{*}{ Geral } & 1 & \multirow{3}{*}{41} & 3,00 & 0,00 & 3 & 3 & 3 & 3 & 3 \\
\hline & & 2 & & 3,79 & 0,54 & 1,3 & 3,9 & 4 & 4 & 4 \\
\hline & & 3 & & 2,54 & 0,84 & 0 & 2 & 3 & 3 & 3 \\
\hline & & \multicolumn{2}{|c|}{ Total } & 9,33 & 1,00 & 6,3 & 8,7 & 10 & 10 & 10 \\
\hline \multirow{12}{*}{2} & \multirow{4}{*}{ Manhã } & 1 & \multirow{3}{*}{18} & 2,40 & 0,00 & 2,4 & 2,4 & 2,4 & 2,4 & 2,4 \\
\hline & & 2 & & 3,62 & 1,10 & 0,6 & 4 & 4 & 4 & 4 \\
\hline & & 3 & & 3,42 & 0,41 & 2 & 3,5 & 3,6 & 3,6 & 3,6 \\
\hline & & \multicolumn{2}{|c|}{ Total } & 9,44 & 1,18 & 6,2 & 9,4 & 10 & 10 & 10 \\
\hline & \multirow{4}{*}{ Tarde } & 1 & \multirow{3}{*}{19} & 2,21 & 0,60 & 0 & 2,4 & 2,4 & 2,4 & 2,4 \\
\hline & & 2 & & 3,79 & 0,89 & 0,1 & 4 & 4 & 4 & 4 \\
\hline & & 3 & & 3,60 & 0,00 & 3,6 & 3,6 & 3,6 & 3,6 & 3,6 \\
\hline & & \multicolumn{2}{|c|}{ Total } & 9,61 & 1,04 & 6,1 & 10 & 10 & 10 & 10 \\
\hline & \multirow{4}{*}{ Geral } & 1 & & 2,30 & 0,44 & 0 & 2,4 & 2,4 & 2,4 & 2,4 \\
\hline & & 2 & 37 & 3,73 & 0,97 & 0,1 & 4 & 4 & 4 & 4 \\
\hline & & 3 & & 3,51 & 0,30 & 2 & 3,6 & 3,6 & 3,6 & 3,6 \\
\hline & & \multicolumn{2}{|c|}{ Total } & 9,53 & 1,11 & 6,1 & 10 & 10 & 10 & 10 \\
\hline \multirow{9}{*}{3} & \multirow{3}{*}{ Manhã } & 1 & \multirow{2}{*}{7} & 4,31 & 1,16 & 2 & 3,5 & 5 & 5 & 5 \\
\hline & & 2 & & 2,79 & 2,46 & 0 & 0 & 4,5 & 5 & 5 \\
\hline & & \multicolumn{2}{|c|}{ Total } & 7,10 & 3,37 & 2,5 & 3,5 & 9,5 & 10 & 10 \\
\hline & \multirow{3}{*}{ Tarde } & 1 & \multirow{2}{*}{13} & 4,94 & 0,16 & 4,5 & 5 & 5 & 5 & 5 \\
\hline & & 2 & & 4,90 & 0,19 & 4,5 & 4,9 & 5 & 5 & 5 \\
\hline & & \multicolumn{2}{|c|}{ Total } & 9,84 & 0,22 & 9,5 & 9,6 & 10 & 10 & 10 \\
\hline & \multirow{3}{*}{ Geral } & 1 & & 4,72 & 0,73 & 2 & 4,8 & 5 & 5 & 5 \\
\hline & & 2 & 20 & 4,16 & 1,74 & 0 & 4,5 & 5 & 5 & 5 \\
\hline & & Tot & & 8,88 & 2,33 & 2,5 & 9,5 & 9,9 & 10 & 10 \\
\hline
\end{tabular}

Nota: $\mathrm{n}=$ número de alunos; $\mathrm{DP}=$ desvio padrão, $\mathrm{Min}=$ menor valor; $Q_{1}=1^{\circ}$ quartil; $\mathrm{Md}=$ mediana; $Q_{3}=3^{\circ}$ quartil, Max $=$ maior valor.

A avaliação da tarefa 3 consistiu de duas questões (5 pontos cada). Para a questão 1, observa-se que pelo menos $75 \%$ da turma da manhã e $50 \%$ da turma da tarde alcançou pontuação máxima. A turma da tarde também obteve ótimo desempenho na questão 2: a pontuação mínima foi 4,5 e $75 \%$ da turma atingiu pontuação máxima. A turma da tarde, por sua vez, não apresentou desempenho satisfatório nesta questão: $25 \%$ da turma alcançou pontuação máxima e $25 \%$ erraram completamente a questão. A pontuação total na avaliação da tarefa 3 evidencia que a turma da tarde, com média 9,84 e nota mínima 9,50, apresentou desempenho homogêneo e bastante superior ao da turma da manhã, com média 7,1 e nota mínima 2,5.

A comparação da pontuação total das turmas nas avaliações mostra que: na tarefa 1 a turma da manhã foi razoavelmente melhor; na tarefa 3 a turma da tarde foi muito melhor; e na tarefa 2 as duas turmas tiveram um desempenho semelhante. A análise da média geral de cada atividade (Tabela 1) permite concluir que o desempenho médio dos alunos foi muito bom nas tarefas 1 e 2 , mas foi um pouco inferior e muito mais heterogêneo na tarefa 3. Acredita-se que a heterogeneidade dos resultados na tarefa 3 se deu pela dificuldade dos alunos em efetuar operações aritméticas de divisão. Deve-se ressaltar, entretanto, que o número de alunos avaliados na tarefa 3 foi muito menor do que 
os avaliados nas tarefas 1 e 2 .

Por fim, foi avaliado o desempenho dos alunos por sexo nas três tarefas, dentro de cada turma. Esses valores são apresentados na Tabela 2. Para a turma da manhã observase que meninas e meninos apresentaram desempenho médio semelhante nas questões $1 \mathrm{e}$ 3 , sendo um pouco mais heterogêneo para as meninas. Na questão 2 os meninos exibiram pontuação média superior e mais homogênea (média 9,88 e desvio padrão 0,3) que a das meninas (média 8,9 e desvio padrão 1,6). Para a turma da tarde, verifica-se que o desempenho das meninas foi ligeiramente superior ao dos meninos nas questões 1 e 3; mas, na questão 2 os meninos se saíram melhor (média 9,91) do que as meninas (média 8,95). De modo geral, é possível concluir que o desempenho dos meninos foi superior e mais homogêneo do que o das meninas.

Tabela 2. Desempenho dos alunos nas três tarefas, por turma e sexo.

\begin{tabular}{|c|c|c|c|c|c|c|c|c|c|c|c|c|c|c|c|c|c|}
\hline \multirow{2}{*}{ Turma } & \multirow{2}{*}{ Tarefa } & \multicolumn{8}{|c|}{ Feminino } & \multicolumn{8}{|c|}{ Masculino } \\
\hline & & $\mathbf{n}$ & Média & DP & Min & $Q_{1}$ & Md & $Q_{3}$ & Max & $\mathbf{n}$ & Média & DP & Min & $Q_{1}$ & Md & $Q_{3}$ & Max \\
\hline \multirow{3}{*}{ Manhã } & 1 & 10 & 9,80 & 0,4 & 8,6 & 9,9 & 10 & 10 & 10 & 11 & 10,0 & 0,0 & 10 & 10 & 10 & 10 & 10 \\
\hline & 2 & 8 & 8,90 & 1,6 & 6,2 & 7,1 & 10 & 10 & 10 & 10 & 9,88 & 0,3 & 9,4 & 9,9 & 10 & 10 & 10 \\
\hline & 3 & 3 & 7,33 & 4,2 & 2,5 & 2,5 & 9,5 & 10 & 10 & 4 & 6,93 & 3,3 & 3,5 & 3,8 & 7,1 & 9,9 & 10 \\
\hline \multirow{3}{*}{ Tarde } & 1 & 7 & 8,90 & 1,3 & 7,0 & 7,7 & 9,8 & 10 & 10 & 13 & 8,71 & 1,1 & 6,3 & 8 & 8,7 & 9,9 & 10 \\
\hline & 2 & 6 & 8,95 & 1,7 & 6,1 & 7,2 & 10 & 10 & 10 & 13 & 9,91 & 0,3 & 8,8 & 10 & 10 & 10 & 10 \\
\hline & 3 & 4 & 9,88 & 0,3 & 9,5 & 9,6 & 10 & 10 & 10 & 9 & 9,83 & 0,2 & 9,5 & 9,6 & 10 & 10 & 10 \\
\hline
\end{tabular}

\subsection{Resultados do Teste Aplicado Antes e Depois da Execução das Atividades}

A Tabela 3 apresenta a pontuação dos alunos no teste, por questão e total. O ganho foi mensurado pela diferença entre as notas do pós e do pré-teste. Para ambas as turmas, a média da questão 1 no pré-teste foi ligeiramente superior a média desta questão no pósteste. Por outro lado, na questão 2 a média do pós-teste foi superior a do pré-teste para a turma da tarde, mas foi inferior para a turma da manhã. Na pontuação geral, verifica-se que a turma da manhã obteve um ganho médio de $-0,06$ e a turma da tarde de 0,34 . Tanto nas questões individuais quanto no total de pontos o ganho foi muito baixo.

Tabela 3. Pontuação dos alunos no teste efetuado antes e depois e ganho com execução da atividade, por turma e geral.

\begin{tabular}{|c|c|c|c|c|c|c|c|c|c|c|}
\hline \multirow{2}{*}{ Turma } & \multirow{2}{*}{ Medida } & \multicolumn{3}{|c|}{ Questão 1} & \multicolumn{3}{|c|}{ Questão 2} & \multicolumn{3}{|c|}{ Total } \\
\hline & & Antes & Depois & Ganho & Antes & Depois & Ganho & Antes & Depois & Ganho \\
\hline Manhã & Média & 1,06 & 1,09 & 0,03 & 1,56 & 1,47 & $-0,09$ & 2,63 & 2,56 & $-0,06$ \\
\hline$(n=16)$ & DP & 0,25 & 0,58 & 0,53 & 0,81 & 0,85 & 0,52 & 0,89 & 1,14 & 0,66 \\
\hline Tarde & Média & 1,11 & 1,26 & 0,16 & 1,50 & 1,68 & 0,18 & 2,61 & 2,95 & 0,34 \\
\hline$(n=19)$ & DP & 0,46 & 0,45 & 0,50 & 0,83 & 0,75 & 0,96 & 1,06 & 0,85 & 1,16 \\
\hline Geral & Média & 1,09 & 1,19 & 0,10 & 1,53 & 1,59 & 0,06 & 2,61 & 2,77 & 0,16 \\
\hline$(n=35)$ & DP & 0,37 & 0,52 & 0,51 & 0,81 & 0,79 & 0,79 & 0,97 & 1,00 & 0,97 \\
\hline
\end{tabular}

A significância desses ganhos foi verificada através do teste $t$ para amostras pareadas, $\operatorname{com} \alpha=0,05$, por turma e geral. Os resultados dos testes são resumidos na Tabela 4. A hipótese sob verificação neste teste supõe que o ganho médio dos alunos não difere de zero. Em todos os três testes, a hipótese de nulidade não foi rejeitada, significando que o ganho médio dos alunos com a execução dessa atividade não foi significativo. Comparando os resultados do pós teste com os resultados das avaliações nas tarefas, percebeu-se uma discrepância no desempenho apresentado pelos alunos. No pós teste as turmas acertaram em média $70 \%$ das questões, o que evidencia desempenho inferior àquele obtido nas 
avaliações das tarefas, onde as médias gerais foram próximas de 9,0. Esta diferença entre os resultados das avaliações e do pós-teste talvez possa ser explicada por uma deficiência do teste na aferição das habilidades dos alunos. É provável que o instrumento de avaliação (questões 1 e 2 do teste) não tenha sido adequado, uma vez que não refletiu os resultados percebidos em sala de aula. Esta avaliação foi importante para que um novo instrumento fosse criado para as atividades a serem desenvolvidas no ano de 2014, visando à melhor avaliação dos conhecimentos e habilidades trabalhados na atividade Números Binários.

Tabela 4. Teste de significância para a variável ganho, por turma e geral.

\begin{tabular}{ccccc}
\hline Turma & Ganho médio & Valor da hipótese & $\mathbf{T}$ & Valor p \\
\hline Manhã & $-0,06$ & 0 & $-0,382$ & 0,7081 \\
Tarde & 0,34 & 0 & 1,291 & 0,2131 \\
\hline Geral & 0,16 & 0 & 0,960 & 0,3438 \\
\hline
\end{tabular}

\section{Considerações Finais}

Este artigo contribui com uma detalhada proposta metodológica da atividade NB, visando colaborar com o desenvolvimento de habilidades como representar, contar, correlacionar e ordenar, trabalhando conceitos como abstração e representação de dados no processo de organização apropriada de informações, com crianças do quarto ano da rede pública, no Ensino Fundamental.

A descrição detalhada da atividade NB, seu desenvolvimento em sala de aula e os resultados obtidos com sua aplicação são reportados em tabela de desempenho (sexo e/ou turma) dos alunos, de acordo com os dois métodos propostos: (i) resultados referentes às tarefas que os alunos realizaram durante a atividade e, (ii) resultados do teste aplicado antes e após a execução de todas as atividades. Os resultados positivos com tarefas que os alunos realizaram durante a atividade NB incentivam novas edições da proposta, considerando outras habilidades do PC, em continuidade do projeto. Os resultados do teste aplicado prévia e posteriormente ao desenvolvimento da atividade NB, apesar de não terem apresentado resultados tão satisfatórios como as avaliações das tarefas da atividade, permitiram perceber a necessidade de melhorias no instrumento.

A atividade piloto NB foi importante em dois principais aspectos:

- permitindo primeiro contato dos alunos graduandos dos cursos de Ciência e Engenharia de Computação com a prática de ensino em escolas de ensino fundamental, da rede pública e na periferia.

- abriu espaço para maior interação entre Universidade e Rede Pública de Ensino Fundamental, incluindo discentes, docentes e gestores e considerando ainda, novas edições e melhorias na organização e metodologias de futuras propostas de trabalho do projeto envolvendo PC.

\section{Referências}

Andrade, D. et al. (2013). Proposta de atividades para o desenvolvimento do pensamento computacional no ensino fundamental. In WIE 2013, pages 169-178.

Barr, V. and Stephenson, C. (2011). Bringing computational thinking to k-12: what is involved and what is the role of the computer science education community? ACM Inroads, 2(1):48-54. 
Bell, T., Witten, I. H., and Fellows, M. F. (2010). Computer Science Unplugged.

Bundy, A. (2007). Computational thinking is pervasive. Journal of Scientific and Practical Computing, 1:67-69.

Carnegie Mellon (2013). Center for Computational Thinking. http://www.cs.cmu.edu/ CompThink/. Acesso: maio/2013.

CSTA, ISTE, and NSF (2010). Computational thinking leadership toolkit. http://www.csta.acm.org/Curriculum/sub/CompThinking.html. Acesso: agosto/2013.

Deng, Z., Huang, W., and Dong, R. (2009). Discussion of ability cultivation of computational thinking in course teaching. In Proc. ICETC'09, pages 197-200.

Denning, P. J. (2009). The profession of it: Beyond computational thinking. Commun. $A C M, 52(6): 28-30$.

França, R. S. and Amaral, C. J. H. (2013). Proposta metodológica de ensino e avaliação para o desenvolvimento do pensamento computacional com o uso do scratch. In Anais do XIX Workshop de Informática na Escola (WIE 2013).

Google (2013). Exploring computational thinking. http://www.google.com/edu/computational-thinking/. Acesso: maio/2013.

Hambrusch, S. et al. (2009). A multidisciplinary approach towards computational thinking for science majors. In SIGCSE 2009, pages 183-187. ACM.

ISTE (2013). Operational definition of computational thinking. http://www.iste.org/learn /computational-thinking/ct-operational-definition. Acesso: maio/2013.

Kafura, D. and Tatar, D. (2011). Initial experience with a computational thinking course for computer science students. In SIGCSE 2011, pages 251-256. ACM.

Lee, I. et al. (2011). Computational thinking for youth in practice. ACM Inroads, 2(1):3237.

Nunes, D. J. (2011). Ciência da computação na educação básica. http://www.jornalda ciencia.org.br/Detalhe.jsp?id=79207. Acesso: maio/2013.

PUC-Rio (2013). Scalable Game Design Brasil. http://www.serg.inf.puc-rio.br/wiki/ index.php. Acesso: agosto/2013.

Repenning, A., Webb, D., and Ioannidou, A. (2010). Scalable game design and the development of a checklist for getting computational thinking into public schools. In Proc. 41st Tech. Symp. on Comp. Sci. Education, pages 265-269, New York, USA. ACM.

Scaico, P. D. et al. (2012). Um relato de experiências de estagiários da licenciatura em computação com o ensino de computação para crianças. RENOTE, 10(3).

UFPel (2014). EXP-PC - Explorando o Pensamento Computacional para a Qualificação do Ensino Fundamental. http://wp.ufpel.edu.br/pensamentocomputacional. Acesso: junho/2014.

Wing, J. M. (2006). Computational thinking. Commun. ACM, 49(3):33-35.

Yinnan, Z. and Chaosheng, L. (2012). Training for computational thinking capability on programming language teaching. In Proc ICCSE'12, pages 1804-1809. 